\title{
Real-Time Control of Rainwater Harvesting Systems: The Benefits of Increasing Rainfall Forecast Window
}

\section{Wei D. Xu ${ }^{1 *}$, Tim D. Fletcher ${ }^{1}$, Matthew J. Burns ${ }^{1}$ and Frédéric Cherqui ${ }^{1,2}$}

${ }^{1}$ School of Ecosystem and Forest Sciences, The University of Melbourne, 500 Yarra Boulevard, Burnley, Victoria 3121 Australia.

${ }^{2}$ Univ. Lyon, INSA Lyon, DEEP EA 7429, F-69621, Villeurbanne cedex, France.

Corresponding author: Wei D. Xu (danielweixu@gmail.com)

\section{Key Points:}

- Four contrasting Real-Time Control strategies were applied to simulated rainwater harvesting systems

- Long lead-time rainfall forecast (7-day) enhanced the ability to reduce flood risk and restore baseflow, with little impact on water supply efficiency

- Using long lead-time rainfall forecast has the potential to holistically restore natural flow regimes.

This is the author manuscript accepted for publication and has undergone full peer review but has not been through the copyediting, typesetting, pagination and proofreading process, which may lead to differences between this version and the Version of Record. Please cite this article as doi: 10.1029/2020WR027856

This article is protected by copyright. All rights reserved. 
Use of Real-Time Control (RTC) technology in Rainwater Harvesting Systems (RWH) can improve performance across water supply, flood protection, and environmental flow provision. Such systems make the most of rainfall forecast information, to release water prior to storm events and thus minimise uncontrolled overflows. To date, most advanced applications have adopted 24-hr forecast information, leaving longer-term forecasts largely untested. In this study, we aimed to predict the performance of four different RTC strategies, based on different forecast lead-time and preferred objectives. RTC systems were predicted to yield comparatively slightly less harvested rainwater than conventional passive systems, but delivered superior performance in terms of flood mitigation and delivery of environmental water for streamflow restoration. More importantly, using a 7-day rainfall forecast was shown to enhance the ability of RTC in mitigating flood risks and delivering an outflow regime that is close to the natural (reference) streamflow. Such a finding suggests that RTC combined with 7-day forecast can enhance the functionality of rainwater harvesting systems to restore and even mimick the entire natural flow regimes in receiving streams. This also opens up a new opportunity for practitioners to implement smart technology in managing urban stormwater in a range of contexts and for a range of stream health objectives.

\section{Plain Language Summary}

'Smart tanks' based on Real-Time Control (RTC) is increasingly used in rainwater harvesting systems to address water shortages, urban flooding and streams depleted of flow. Smart tanks, controlled by RTC, can use a range of digital information (e.g. rainfall forecast) to make optimal decisions to release some tank water before heavy rain, to reduce flood risks, while still supply water to households. Globally, most uses of this technology use 1-day forecasts of rainfall. To understand the effect of longer prediction window, we compared four strategies using either 1-day or 7-day rainfall forecast and modelled their performance using specialized computer code. We found that smart tanks using 7-day rainfall forecasts are superior in reducing urban flood risks and restoring baseflows to streams. More importantly, they can release the tank water in a pattern that is similar to natural streamflow, thus helping to restore and sustain healthy waterway habitats. Our study is the first reported application of 7-day forecast information in smart control rainwater tanks. It opens up a new opportunity in managing urban water in a range of contexts and for a range of stream health objectives.

\section{Introduction}

Urbanisation poses a range of critical challenges in water management. Water scarcity results from population growth and dwindling freshwater resources (Vörösmarty et al., 2010). The growth of impervious cover creates gross changes to the natural water cycle through reductions in infiltration and evapotranspiration (Barron et al., 2013; Haase, 2009), resulting in excessive stormwater runoff and concurrently decreased groundwater recharge (Bultot et al., 1990). This increases flooding risks (Nirupama \& Simonovic, 2006) and perturbs the natural flow regimes, increasing peak flows and reducing baseflow (Booth \& Jackson, 1997; Burns et al., 2012b; Price, 2011). Accordingly, the conventional hydraulic efficient drainage network, which directly connects the impervious runoff to receiving water, increases the frequency, magnitude and volume of storm flow (Leopold, 1968) and reduces storm recession time (Burns et al., 2005). Such a change drives channel erosion (Hammer, 1972; Russell et al., 2020) and ecological degradation in urban streams and leads to a subsequent loss of ecosystem services (Bunn \& Arthington, 2002; King et al., 2005; Walsh et al., 2012). Similarly, loss of baseflow, results in loss of dry weather wetted habitat, thus further reducing biodiversity (Poff et al., 1997). 
Urban stormwater impacts can be mitigated using Stormwater Control Measures (SCMs) such as Rainwater Harvesting Systems (RWH). Such systems are conventionally designed to capture and store surface runoff from impervious cover (e.g. roofs) to provide a source of water (Gardner \& Vieritz, 2010; Mikkelsen et al., 1999). Diversion of rainwater from direct runoff to end-use also helps to mitigate the excess runoff delivered to receiving waters (Fletcher et al., 2007), thus reducing the risks of flooding (Schubert et al., 2017). However, there is an increasing recognition of the importance of SCMs being able to not only reduce peak flows, but also to restore lost baseflows (Hamel et al., 2013; Price, 2011; Walsh et al., 2016). As an example, in Melbourne, Australia, a new stormwater regulation has been piloted, incorporating requirements to both reduce runoff volume and frequency, as well as to make contributions to baseflow (DELWP, 2019). Releasing some of the retained rainwater, through a passive orifice, in a temporal pattern close to the natural flow regimes can help to restore baseflow (Burns et al., 2012a). One limitation of such a system, however, is that they often lack the constant and high demand to create sufficient headroom for upcoming storm runoff (DeBusk et al., 2013; Jones \& Hunt, 2010), thus leading to frequent uncontrolled system overflows.

Real-Time Control (RTC), so called "smart" technology, is increasingly applied in RWH systems to maximise simultaneous outcomes related to water supply, flooding, and baseflow provision (Roman et al., 2017; Xu et al., 2018). One major advantage of RTC compared to conventional (i.e. passive) systems is the ability to use the available information (e.g. environmental monitoring and weather forecast) and adapt the system operation in coherence with the real-time situation (Kerkez et al., 2016). RTC systems are generally equipped with an active outlet and designed to release water prior to the event (termed here as pre-storm release) to minimize the magnitude and frequency of uncontrolled overflow. The released volume is determined by comparison of rainfall forecast from the local meteorological authority with current available headroom. Both modelling and empirical studies have demonstrated the ability of RTC in enhancing the stormwater retention and peak flow reduction (Di Matteo et al., 2019; Gee \& Hunt, 2016; Liang et al., 2019), with very little detriment to water supply (Xu et al., 2018). Recent application also includes a new possibility to restore the stream baseflow through a persistent low-rate discharge that emulates the natural flow regimes (Xu et al., 2018).

One important concern in relation to the pre-storm release is that without attention to the flow regime, it could simply mimic the 'uncontrolled' overflow, but shifted in time, thus leaving the flow regime highly disturbed, with geomorphic and ecological consequences for downstream receiving waters. This is because most such RTC applications for flood mitigation are managed at best using a 24-hr forecast, meaning that the release needs to be rapid in order to be completed before the predicted rainfall. Therefore, system outflow is likely to retain the magnitude and flashiness of peak flows which are a feature of impervious runoff, potentially a posing risk of erosion and degradation to downstream receiving waters. The main questions addressed in this article are related to the optimal use of available forecast with different lead-time and its impact for the overall performance of an RTC rainwater harvesting system.

Globally, Numeric Weather Prediction (NWP) can anticipate rainfall events more than 24-hours ahead of their arrival, with forecasts of up to 7-days readily available (Clark \& Hay, 2004; Damrath et al., 2000; Davies et al., 2005). While the accuracy of forecast remains a fruitful area of research, such an advance drives new improvement in water industry, such as hydrological forecasting (Georgakakos \& Hudlow, 1984; Rossa et al., 2011). Operation based on 7-day rainfall forecast has been used in agriculture (Cai et al., 2011; Wang \& Cai, 2009) and water supply (Tsai et al., 2008; Westphal et al., 2003). In theory, this would also 
allow RTC systems to perform pre-storm release long before the actual event, at a lower rate that is much closer to the natural hydrology. However, the use of 7-day forecast and the associated effect on pre-storm release remain largely untested.

In this study, we aim to design a RTC strategy to operate RWH and assess its effects using different forecast lead-times. We have developed and modelled four RTC strategies with different preferences in terms of maximizing the benefits for water supply, flood protection or streamflow preservation. These strategies are also based on contrasted forecast lead-times and are compared to a conventional (without any passive release) system during a 5.5-year simulation period. In a more detailed analysis, the impact of different RTC strategies on system outflow regimes is characterized and compared to the natural streamflow.

We hypothesis that systems using longer lead-time forecasts could improve the ability of RTC in flood protection, with little detriment to the supply of end-use. Our results confirmed this hypothesis and found that, by using the 7-day forecast, the benefits of RTC are not limited in reducing the peak flow and enhancing the baseflow. Importantly, it can deliver an outflow regime that is close to the reference streamflow, revealing a promising potential of RTC to restore and even mimick the entire natural flow regime. Our work brings valuable insights on both the advantage and trade-off of this technology and different forecast information. It highlights the substantial opportunity in equipping rainwater harvesting systems with RTC for a wide range of simultaneous water supply, flood mitigation and streamflow restoration objectives.

\section{Methodology}

\subsection{Proposed RTC Strategies}

We developed four RTC strategies which utilised the rainfall forecast in different ways (Table 1). Strategy S1 (Flood Protection) is designed to minimise tank overflows through a 24-hr uniform release (termed here as 'pre-storm release') of any overflows that are forecast to occur within the next 7-days. Strategy S2 (Supply Maximisation) is similar to S1, but features a much shorter forecast lead-time (1-day) in order to increase the amount of tank water available for supply (i.e. the pre-storm release is not done until the day of predicted overflow, to reduce the probability of any discharges that turn out not to have been required to prevent overflows). In contrast, the pre-storm release in strategy S3 (Longest Discharge) and S4 (Streamflow Preservation) were designed to minimize the flashiness and magnitude of pre-storm release using the 7-day forecast to extend the discharge period, thus more closely reflecting natural streamflow. This is achieved by designing the release in $S 3$ with the longest possible discharge duration for each predicted overflow volume. In $S 4$, the lowest possible discharge rate is used, to minimise changes to the flow regime.

Consider the following as an example. Assuming the demand patterns are the same for four RTC strategies (i.e. demand patterns are explained in section 2.4). If overflow was predicted on both day 3 and 6 over the next 7 days, Flood Protection would release all of the predicted overflow volume on day 1 to minimise the risk of overflow, while Supply Maximisation would release on the day(s) of predicted overflow (i.e. day 3 and 6). Under the Longest Discharge strategy, these overflows would be uniformly released over 2 and 5 days respectively to maximize the duration of pre-storm release associated to each event. Such a decision is then recalculated under the Streamflow Preservation strategy to minimize the peak release rate during the 7-day, while still preventing each predicted overflow (Table 1).

While the above all aim to reduce uncontrolled overflow, all RTC strategies were also designed to simultaneously restore some stream baseflow. This is achieved by a persistent 
160 (i.e. every time-step) controlled discharge (termed here as 'baseflow release') which attempts

161 to counteract the lost baseflows common in urban streams (Price, 2011; Smakhtin, 2001).

162 Such an operation is ceased when pre-storm release is required, or if the storage is empty (i.e.

163 blue area in Example Table 1). The baseflow release target was determined by the median

164 flow (i.e. daily Q50) from a reference natural stream (forested catchment); the median flow

165 provides a reasonable estimate of a stream's baseflow (Smakhtin et al., 1997). 
167 Four Proposed Real-Time Control Strategies.

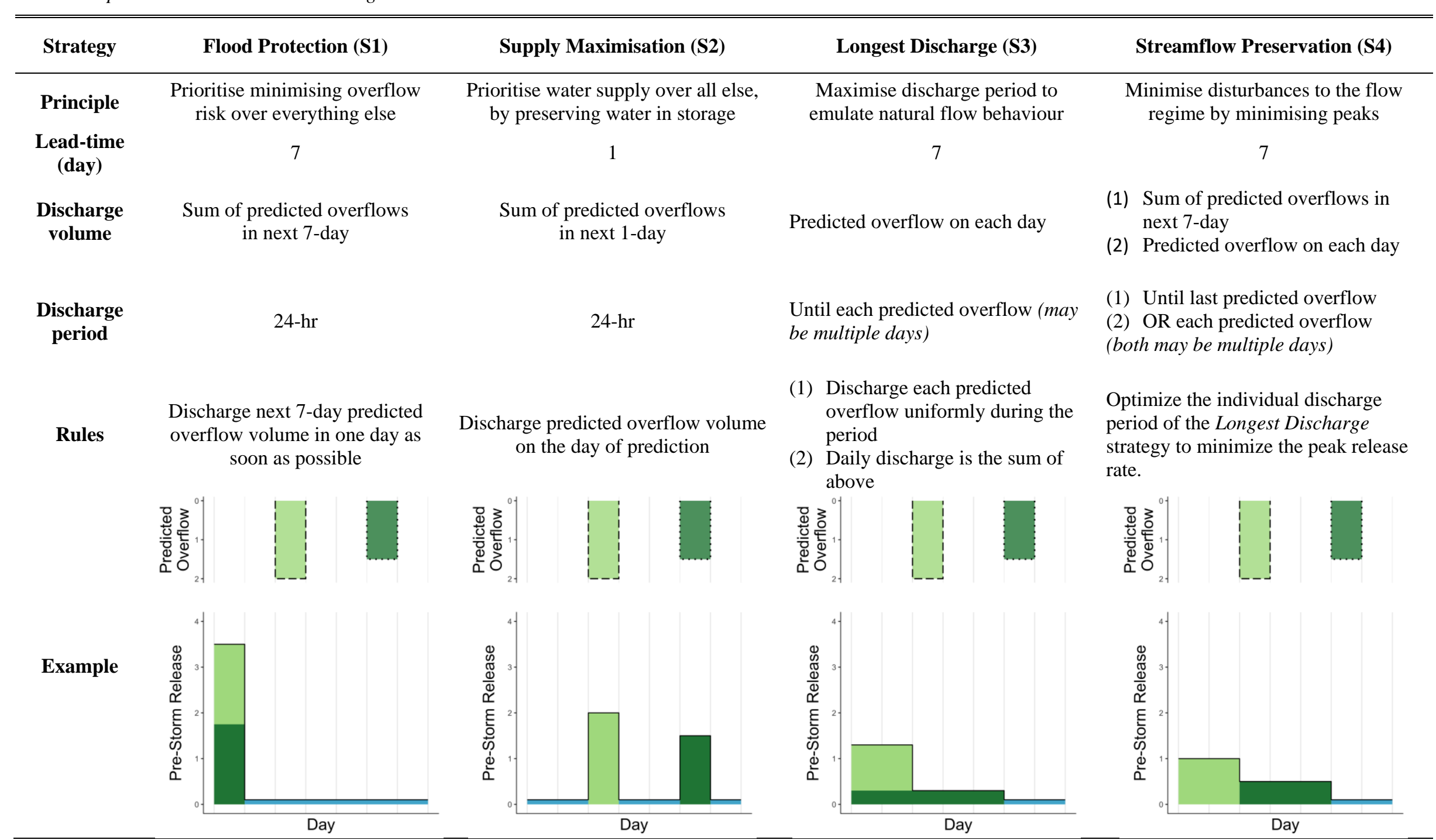

This article is protected by copyright. All rights reserved. 
A modelling framework, written using $\mathrm{R}$ (version 3.6.1), was developed to simulate the performance of the proposed RTC system under the four proposed strategies. This framework includes three different modules: prediction (M1), simulation (M2), and assessment metrics (M3) (Figure 1). The prediction module (M1) is run at a daily timestep (at $3 \mathrm{pm}$ ), the simulation (M2) is run every 6 minutes and the assessment (M3) is the integration of all the 6-minutes step for the whole time series.

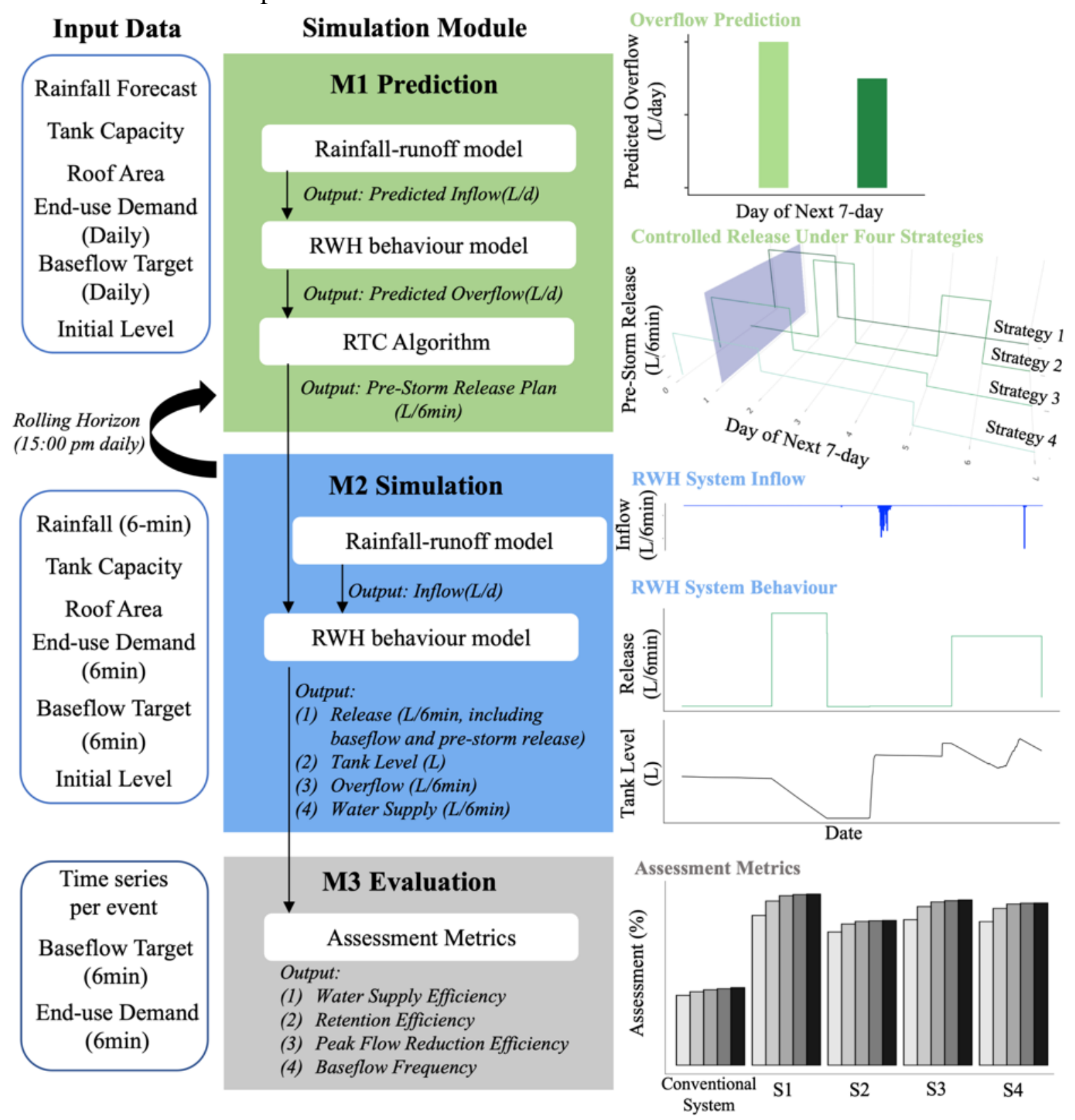

Figure 1. Conceptual representation of modelling framework to simulate and evaluate real-time controlled rainwater harvesting systems. Conventional system is simulated only by M2 and evaluated by M3. 


\subsubsection{M1 Prediction}

The prediction module is the central component to decide control actions for different RTC strategies. It consists of three steps which are operated daily. Firstly, it predicts system inflow as a function of rainfall forecast data (Equation 1, Rainfall-runoff model):

$$
\mathrm{Q}_{\text {in }}=\left(\mathrm{R}_{\mathrm{t}}-\mathrm{R}_{\text {loss }}\right) \times \mathrm{A}
$$

Where $Q_{\text {in }}$ is the system inflow $(L), R_{t}$ is the forecast rainfall depth $(\mathrm{mm})$ at time $t, \mathrm{R}_{\text {loss }}$ is the initial loss (i.e. depression storage on the roof surface that delay the runoff) which is set as $0.2 \mathrm{~mm} /$ day. A is the roof size which is selected as $150 \mathrm{~m}^{2}$ to reflect a residential house.

Tank level is then sampled to predict future system overflow using Yield-AfterSpillage rules which provides a more accurate estimation of yield (Fewkes \& Butler, 2000; Jenkins et al., 1978) (Equations 2-5, Rainwater Harvesting Behaviour Model). Overflows in any systems are unregulated - i.e. they occurred whenever inflows exceeded system capacity. First flush was excluded in the tank behavioral model, given that the use, type and volumetric behaviour of filtration devices is highly variable.

$$
\begin{gathered}
Q_{o t}=\max \left\{\begin{array}{c}
V_{t-1}+Q_{\text {in }}-S \\
0
\end{array}\right. \\
Q_{b t}=\min \left\{\begin{array}{l}
Q_{\text {target }} \\
\mathrm{V}_{\mathrm{t}-1}
\end{array}\right. \\
\mathrm{Y}_{\mathrm{t}}=\min \left\{\begin{array}{c}
\mathrm{D}_{\mathrm{t}} \\
\mathrm{V}_{\mathrm{t}-1}-\mathrm{Q}_{\mathrm{bt}}
\end{array}\right. \\
\mathrm{V}_{\mathrm{t}}=\min \left\{\begin{array}{c}
\mathrm{V}_{\mathrm{t}-1}+\mathrm{Q}_{\text {in }}-\mathrm{Y}_{\mathrm{t}}-\mathrm{Q}_{\mathrm{bt}} \\
\mathrm{S}-\mathrm{Y}_{\mathrm{t}}-\mathrm{Q}_{\mathrm{bt}}
\end{array}\right.
\end{gathered}
$$

Where $\mathrm{V}_{\mathrm{t}}$ and $\mathrm{V}_{\mathrm{t}-1}$ are the volume in store (L) at the end of time step $\mathrm{t}$ (current) and $\mathrm{t}-1$ (previous) respectively, $Y_{t}$ is the rainwater yield at $t(L / t i m e s t e p), Q_{b t}$ is the controlled release (i.e. baseflow release in prediction module) at $\mathrm{t}\left(\mathrm{L} /\right.$ timestep), $\mathrm{Q}_{\mathrm{ot}}$ is tank overflow at $\mathrm{t}\left(\mathrm{L} /\right.$ timestep), $\mathrm{S}$ is tank size $(\mathrm{L}), \mathrm{D}_{\mathrm{t}}$ is rainwater demand at $\mathrm{t}$ (L/timestep), $\mathrm{Q}_{\text {target }}$ is the baseflow target at $\mathrm{t}$ (L/timestep), $\mathrm{Q}_{\text {in }}$ is the tank inflow (L/timestep)

Finally, four pre-storm release plans are developed based on strategies (previously explained in 2.1) and fed into the M2 simulation.

\subsubsection{M2 Simulation}

This module simulates the performance of the defined controls. The modelling process is similar to the prediction module in simulating system inflow and system behaviour. However, this module uses the actual observed rainfall, applying an initial loss of $0.2 \mathrm{~mm}$ (Laing et al., 1988), with an antecedent drying period of 2 hours (i.e. initial loss is only applied when there is a minimum of 2-hour dry period). As noted above, the tank behavioural model is run on a 6-min timestep, which is sufficient to capture system dynamics (Di Matteo et al., 2019; Mitchell et al., 2008).

The prediction (forecast) and simulation (observed) modules are run on a rolling horizon. The prediction module decides the controlled release for the next 7-day based on the rainfall forecast (i.e. 15:00 pm daily). However, only the control actions in the next 24-hour are implemented in the simulation modules. This is then renewed, on a daily basis, when forecast information is updated. Finally, the outputs from the simulation module are stored and evaluated by assessment metrics at the end of simulation period. 


\subsection{Assessment Metrics}

Four metrics were selected to quantify the long-term performance on supply and flow regimes (Table 2). The baseflow frequency, retention and supply efficiency are based on total timesteps or volume, while the peak flow mitigation is evaluated in each event. An individual storm event was defined as having more than $0.2 \mathrm{~mm}$ of rainfall and $1.2 \mathrm{~mm} / \mathrm{hr}$ rainfall intensity with an antecedent dry period of at least $2 \mathrm{~h}$, which is consistent with initial loss. The performance of different strategies is compared in the main text (see Section 3.1 and 3.2) by taking a mean of each assessment metric across five tank sizes, with detailed results presented in Figure 2. Finally, four of the largest events (i.e. max intensity $(\mathrm{mm} / \mathrm{hr}$ ) while duration is no less than 30min) were selected as examples to demonstrate peak flow mitigation.

The system outflow is also characterized using a flow duration curve. System outflow is defined as the sum of any uncontrolled overflow and any controlled release (i.e. pre-storm release and baseflow release). The outflow regime of four RTC strategies is then compared to conventional system (i.e. overflow) and the reference streamflow.

\section{Table 2.}

Assessment Metrics for Triple Objectives of Rainwater Harvesting

$\begin{array}{ll}\begin{array}{c}\text { Assessment } \\ \text { Metrics }\end{array} \text { Equation } & \text { Description }\end{array}$

$\begin{aligned} & \text { Water Supply } \\ & \text { Efficiency (\%) }\end{aligned} \quad E w s=\frac{\sum Y_{t}}{\sum D_{t}} \times 100 \%$

Retention

Efficiency (\%)

$E_{R}=\left[1-\frac{\sum Q_{o t}}{\sum A \times R_{t}}\right]$

Peak Flow Mitigation (\%)

$$
\rho=\frac{Q_{\text {out }, \text { max }_{\text {convention system }}}-Q_{\text {out }, \text { max }_{R T C \text { system }}}}{Q_{\text {out }, \text { max }_{\text {convention system }}}}
$$

Baseflow

Frequency (\%)

$$
\begin{gathered}
N_{t}=\left\{\begin{array}{c}
1,2 * Q_{\text {target }} \geq Q_{b t} \geq Q_{\text {target }} \\
0, \text { else }
\end{array}\right. \\
F_{b}=\frac{\sum N_{t}}{n}
\end{gathered}
$$

$\mathrm{Y}_{\mathrm{t}}$ is the rainwater yield on supply at time $\mathrm{t}\left(\mathrm{L} / 6\right.$ minutes), $\mathrm{D}_{\mathrm{t}}$ is household demand at time $\mathrm{t}$ (L/6minutes)

$\mathrm{Q}_{\mathrm{ot}}$ is overflow at time $\mathrm{t}(\mathrm{L} / 6$ minutes), A is roof size (i.e. $150 \mathrm{~m}^{2}$ ), $\mathrm{R}_{\mathrm{t}}$ is roof runoff at time $\mathrm{t}(\mathrm{mm} / 6 \mathrm{minutes})$

Peak flow reduction efficiency of RTC strategies compared to the conventional system. $Q_{\text {out }}$ refers to overflow in conventional system and sum of overflow and release in RTC systems

$N_{t}$ is count if baseflow target is satisfied at time $t$ and $n$ is the total number of timesteps. 
Numeric Weather Prediction was obtained from the local meteorological authority (Bureau of Meteorology, 2020) to predict uncontrolled overflow, which is based on the Australian Community Climate Earth-System Simulator (ACCESS) (Bureau of Meteorology, 2010). In total, 66 months (i.e. 2014-03-01 - 2019-08-31) of 7-day lead precipitation forecast were extracted for Eastern Melbourne (i.e. Lat:-37.92, Long:145.32). We utilized mean daily predicted rainfall (in $\mathrm{mm}$ ) which is updated daily at 15:00 pm and has a relative error of 9.5\% compared to rainfall observation (i.e. forecast rainfall generally underestimates the actual rainfall).

Rainfall and streamflow observations were obtained at the same location during the same period, to compute system inflow (M2) and the baseflow release target (M1\&M2) respectively. We extracted 550 rainfall events with an annual rainfall of $861 \mathrm{~mm}$. Four baseflow targets were derived from median flow across the four seasons (to account for seasonal various), with mean of $0.26 \mathrm{~mm} /$ day.

We also simulated five scenarios to represent a range of household settings in terms of tank size and roof size. We considered a roof of $150 \mathrm{~m}^{2}$, drained by five different sized storage tanks $(2,3.75,7.5,11.25,15 \mathrm{~kL})$, and are connected to a range of domestic water demands, including toilet flushing, dishwasher and cloth washing. The demand profile was adopted from $\mathrm{Xu}$ et al. (2018). It is consistent with a typical indoor diurnal pattern that has the peak consumption of $10.3 \mathrm{~L} / \mathrm{hr}$ at $7 \mathrm{pm}$ and the lowest usage of $2.4 \mathrm{~L} / \mathrm{hr}$ at $2 \mathrm{am}$, with a total daily consumption of approximately $132 \mathrm{~L} / \mathrm{d}$.

\section{Results}

We predicted and compared system performance in terms of water supply, flood risk mitigation and baseflow restoration. Modelling of the RTC systems predicted them to yield comparatively less water supply than conventional (passive-release) systems, but to be much more effective in reducing flood risks and restoring baseflow. More importantly, using 7-day lead-time rainfall forecast, which offers longer prediction window, was shown to further enhance the ability of RTC in mitigating flood risks and delivering an outflow regime that is close to the reference streamflow.

\subsection{Supply}

According to the results of the simulation (Figure 2), RTC systems using a 1-day rainfall forecast could supply more water for end-use than those which utilise a 7-day prediction window. The Supply Maximisation strategy (S2) demonstrated an average of 7.7\% higher supply efficiency compared to the Flood Protection strategy (S1), with an average (across all tank sizes) water supply volume of $234 \mathrm{~kL}$ (S1) and $255 \mathrm{~kL}$ (S2) over the 5.5 years, respectively. Comparatively smaller reductions in supply efficiency were predicted for the flow regime focused strategies - 3.2\% for Longest discharge strategy (S3) and $2.6 \%$ for Streamflow preservation strategy (S4). Not surprisingly, a conventional system was predicted to yield most water, although differences between all the systems diminished with increasing tank capacity. 


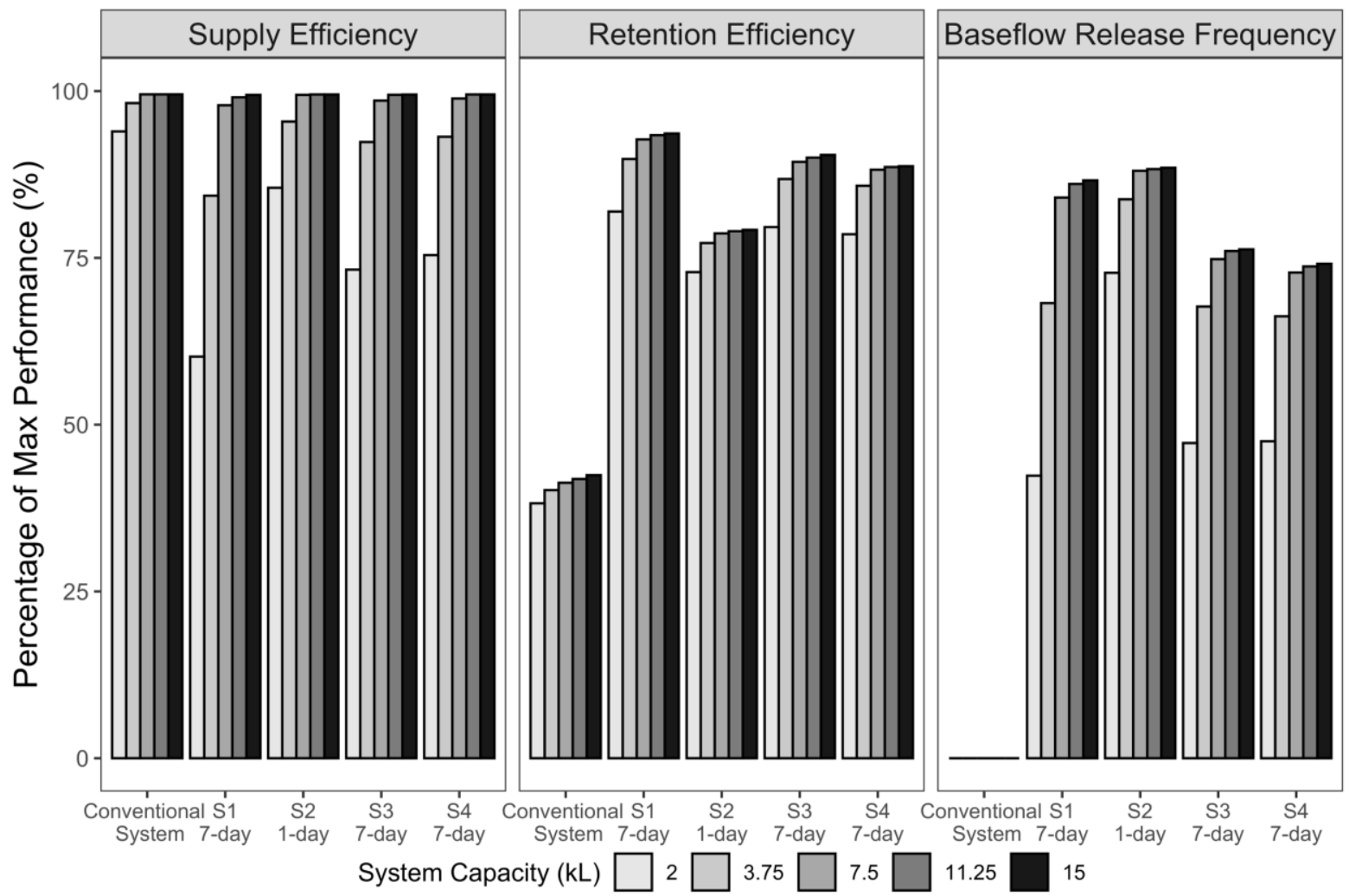

Figure 2. Performance evaluation of conventional system and four RTC systems with different system capacities. Three metrics are used from Table 2 to quantify the performance during the entire simulation period, which are supply efficiency, retention efficiency, and baseflow frequency. The strategies are Flood protection (S1), Supply maximisation (S2), Longest discharge (S3) and Streamflow preservation (S4).

\subsection{Flow Regime}

\subsubsection{Flood risk mitigation}

All RTC systems were predicted to reduce uncontrolled system overflows compared to the conventional system. The Supply Maximisation strategy, using 1-day forecast, nearly doubles the retention efficiency compared to conventional passive systems, with an increase ranging between $72 \%-79 \%$ (Figure 2). Such an improvement is further elevated by use of the 7-day forecast information (i.e. Flood protection, Longest discharge and Streamflow preservation strategies), indicating an average further improvement of $10 \%$, meaning an overflow reduction of $65.7 \mathrm{~kL}$ (i.e. out of $657.5 \mathrm{~kL}$ of the total inflow) during the 5.5 years simulation period. More importantly, the results show that increasing the lead-time from 1 day to 7 days providse a much better flood protection than simply increasing the tank capacity.

RTC using 7-day forecast was also predicted to mitigate flow peaks in both small and large rainfall events (Table 3). For small events (i.e. with rainfall magnitudes less than the design rainfall 5-yr, 1-hr storm), Supply maximisation strategy (S2) with capacity of $7.5 \mathrm{~kL}$ showed more than $30 \%$ reduction in peak flow compared to conventional systems. However, this benefit can be generally increased to $100 \%$ using 7 -day rainfall forecast. For large rainfall events, while 1-day RTC has no difference to conventional system, RTC using 7-day forecast provides better performance in reducing the flow peaks, especially for events no more than 20-year ARI. 
Table 3.

Peak Flow Mitigation of 7.5 kL Systems in Four Large Events.

\begin{tabular}{|c|c|c|c|c|c|c|c|c|c|}
\hline \multirow[b]{2}{*}{ Date } & \multirow[b]{2}{*}{$\begin{array}{l}\text { Depth } \\
(\mathrm{mm})\end{array}$} & \multirow{2}{*}{$\begin{array}{l}\text { Max 30-min } \\
\text { intensity } \\
(\mathrm{mm} / \mathrm{hr})\end{array}$} & \multirow[b]{2}{*}{$\begin{array}{l}\text { Duration } \\
\text { (hr) }\end{array}$} & \multirow{2}{*}{$\begin{array}{c}\text { ARI } \\
\text { approx. }^{\text {b }}\end{array}$} & \multirow[b]{2}{*}{$\begin{array}{l}\text { Forecast } \\
\text { error }(\%)^{\mathrm{a}}\end{array}$} & \multicolumn{4}{|c|}{ Peak Reduction $(\%)$} \\
\hline & & & & & & $\begin{array}{c}\text { S1 } \\
(7-d)\end{array}$ & $\begin{array}{c}\mathrm{S} 2 \\
(1-\mathrm{d})\end{array}$ & $\begin{array}{c}\text { S3 } \\
(7-d)\end{array}$ & $\begin{array}{c}\text { S4 } \\
(7-d)\end{array}$ \\
\hline $\begin{array}{l}29^{\text {th }} \text { March } \\
2016\end{array}$ & 65.09 & 96.4 & 2.3 & $>100$ & -73 & 33.8 & 0 & 0 & 0 \\
\hline $\begin{array}{c}27^{\text {th }} \text { January } \\
2016\end{array}$ & 34.2 & 36.4 & 1.8 & 20 & -49.3 & 100 & 0 & 100 & 99.8 \\
\hline $\begin{array}{c}21^{\text {st }} \text { March } \\
2017\end{array}$ & 22.8 & 22.8 & 1 & 5 & -42.4 & 100 & 30 & 100 & 95 \\
\hline $\begin{array}{c}25^{\text {th }} \text { January } \\
2018\end{array}$ & 13.2 & 26.4 & 0.5 & 2 & -59.7 & 100 & 54.2 & 100 & 100 \\
\hline
\end{tabular}

301

302

303

304

305

306

307

308

309

310

311

312

313

314

315

316

317

318

319

320

321

322

323

324

325

326

327

328

Note: ${ }^{\mathrm{a}} \mathrm{ARI}$ is approximated by the Intensity-Frequency-Duration design rainfalls from the local meteorological authorities (Bureau of Meteorology, 2016), using depth and duration in each event. ${ }^{b}$ Forecast error is the mean relative error of daily rainfall observation and prediction, which is comparable with other study (Shrestha et al., 2013).

To illustrate (Figure 3), the Flood Protection strategy in a $7.5 \mathrm{~kL}$ system mitigated all uncontrolled overflow during the period of 23rd - 31st January 2016, achieving a 100\% peak flow reduction in a 20 year, $2 \mathrm{hr}$-storm on 27 th January. Two overflow events were firstly predicted by 7-day rainfall forecast on 23rd Jan, which occurred on 27th and 28th January. Thus, the pre-storm release was performed in the next 24-hr accordingly at a steady rate of 40L/hr. As the system capacity was adequate to accommodate all predicted inflow, Flood Protection was then returned to routine baseflow release (i.e. $1 \mathrm{~L} / \mathrm{hr}$ ) on 24 th and 25 th January. However, this decision was reassessed when forecast information was updated at 15:00 pm 26th January due to five consecutive overflow predicted. Therefore, the pre-storm release overrode the baseflow release and discharged the storage at $210 \mathrm{~L} / \mathrm{hr}$ until the tank was emptied, leading to $100 \%$ peak flow reduction during a 20 year, $2 \mathrm{hr}$-storm. For the conventional system, the tank spilled most of the inflow through uncontrolled overflow (Figure 3).

Moreover, the peak flow in a long duration rainfall could also be reduced by discharging the storage during the event. Three subsequent events were predicted on 28th January in the next 7-day forecast period, with the largest rainfall happening in the next 24hr. Thus, the Flood protection strategy determined a pre-storm release of $160 \mathrm{~L} / \mathrm{hr}$ to avoid any overflow on the day, while simultaneously making room for future inflow on 29th and 30th January. This is performed during a 6-hr 1 in 1-year event (i.e. 28th January), achieving a peak flow reduction of $87 \%$ compared to conventional systems. Such a control was then decreased to $20 \mathrm{~L} / \mathrm{hr}$ on 29th January due to an over-prediction in the previous forecast. Therefore, RTC using Flood protection strategy successfully mitigated all uncontrolled overflow during the 29th and 30th January event, achieving $98 \%$ and $100 \%$ peak reduction compared to conventional systems respectively. 

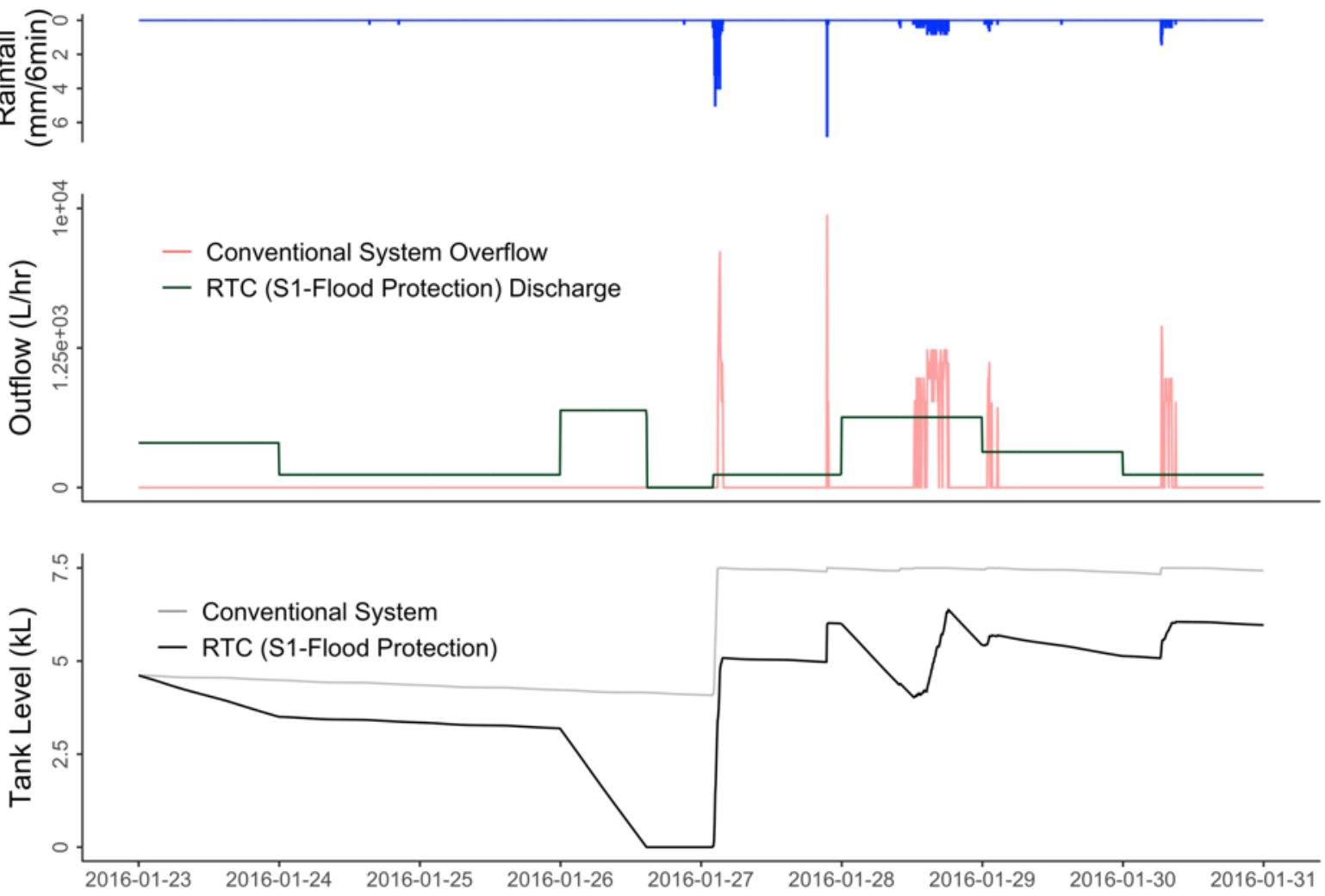

Figure 3. Illustration of a $7.5 \mathrm{~kL}$ system performance for the Flood protection strategy and conventional systems during $23^{\text {rd }}-31^{\text {st }}$ Jan 2016, including hyetograph (top), outflow hydrograph (middle) and water level (bottom). The conventional systems performance was modelled separately using the same initial condition as the Flood protection strategy on $23^{\text {rd }}$ Jan.

\subsubsection{Baseflow Restoration}

The 1-day forecast control was generally able to deliver more frequent baseflow release compared to strategies using 7-day information. The Supply maximisation strategy shows an average of $14.7 \%$ higher baseflow release frequency than system using 7-day forecast (Figure 2). Such an advantage is comparatively larger in small sized systems (e.g. 2 $\mathrm{kL}$ ), diminishing in large systems, demonstrating a similar trend to the observations for water supply efficiency.

For systems using 7-day forecast, baseflow release frequency depended on system capacity. The Flood protection strategy was predicted to deliver more frequent baseflow release than the Longest discharge and the Streamflow protection strategies in large systems (i.e. capacity $\geq 7.5 \mathrm{~kL}$ ), but was the opposite in small sized system. This demonstrates that discharging the pre-storm release early, which potentially lead to less water-in-storage available in the next 7-day, could affect the volume available for the baseflow release, especially in small systems. 


\subsubsection{Outflow Characterization}

In addition to the baseflow release frequency, the outflows of all RTC systems were characterized by a flow duration curve, with a comparison to the reference streamflow (Figure 4). All RTC systems were predicted to successfully restore the low-flow aspects of the flow regimes (Figure 4C). They generally produce higher low flows across the different seasons (i.e. four stages), especially for Q75 - Q99 flows. In contrast, the stream gauge at the reference stream frequently experiences cease-to-flow conditions.

The RTC systems were also shown to reduce the magnitude and flashiness of high flows, especially for systems using 7-day forecast. RTC systems demonstrated lower high flows compared to conventional systems, especially for $<$ Q1 flows (Figure 4B). System using 7-day information further lower the magnitude and rate of change compared to the Supply maximisation strategy, which are vital in restoring the natural flow regime (Poff et al., 1997). More importantly, in the 1-day forecast, the high flow regime of the Supply maximisation strategy almost duplicates the behaviour of the conventional system, while the 7-day forecast period allows the RTC systems to enhance mitigation of peak flows, thus reducing flooding risks. For system using 1-day forecast, despite the lower magnitude, it may overflow almost the same way as conventional systems during large events, which is consistent with the finding in peak reduction (Table 3).

Moreover, designing the pre-storm release to operate over a longer duration at a lower rate could better attenuate the flows, especially during Q5 - Q25 (Figure 4A). The outflow duration curve of Flood Protection and Supply Maximisation shows higher peak flow during Q0.5 - Q3, with a sudden 'drop-off' towards baseflow levels (Figure 4B). In contrast, the outflow regime of the Longest discharge and the Streamflow protection strategies generally produces more muted high flows, decreasing more gradually until the turning point occurred later at Q25. This gives a more constant overall flow regime. Most importantly, these designs more closely resemble the flow duration curve of the reference streamflow.

(a)

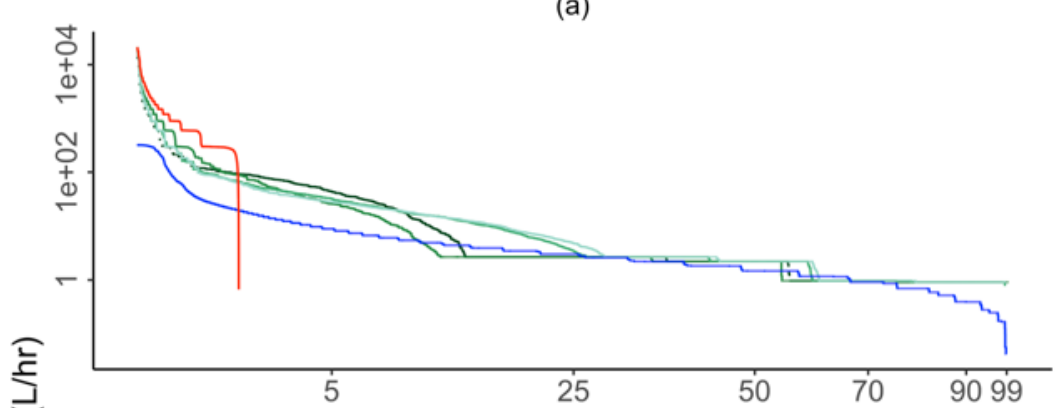

... S1 Flood Protection

- S2 Supply Maximization

- - S3 Longest Discharge

- S4 Streamflow Preservation

- Conventional System

- Reference Streamflow

(b)

(c)
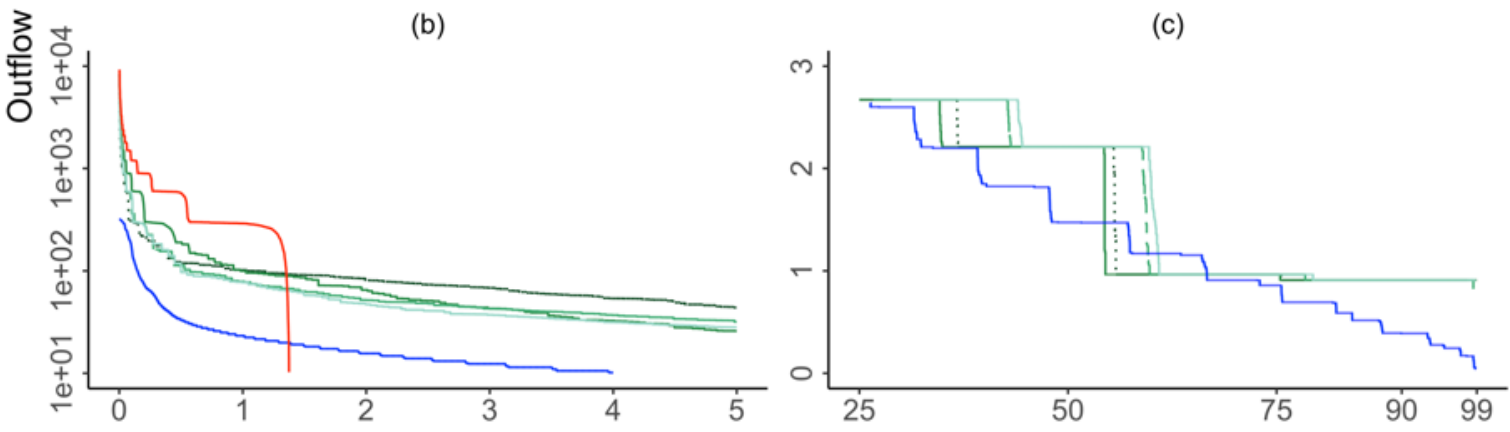

Percentage of Time Flow Exceeded

Figure 4. Outflow Duration Curve of a $7.5 \mathrm{~kL}$ system in conventional setting and four RTC strategies compared to the reference streamflow on a pro-rata base (i.e. considering catchment area of $150 \mathrm{~m}^{2}$ ). System outflow is determined by the sum of overflow and release. 


\section{Discussion}

\subsection{The impact of forecast lead-time}

Applying long lead-time forecast (e.g. 7-day) in RTC may result in small reductions in water supply, but dramatically enhances the performance in reducing flood risk. This is because a longer prediction window, which extends the ability to predict future overflow, results in higher tank volume dedicated to pre-storm release (Figure 5).

The impact of long lead-time forecast on water supply also leads to the same impact on baseflow release. The baseflow release operates a persistent discharge, which is equivalent to a low-but-steady 'demand' (albeit for the environment, rather than human water consumers) on water from the rainwater harvesting system. A previous study has shown that the level of baseflow release we simulated in this study has little detriment to water supply (Xu et al., 2018). Systems controlled with long lead-time forecast will release more water for flood mitigation, and thus hold less water to supply baseflow release, consistent with the effect observed for (human) water supply. The impact of the strategy on the storage available is confirmed when representing the storage duration curve for the four RTC strategies and the conventional tanks, for the 5.5-year simulation period (Figure 5).

As shown in Figure 2, the system capacity impacts the performance of the system. A RTC system using 1-day forecast may supply more end-use and baseflow release in small systems (where limitations on available water are amplified), but such a difference is diminished with increased tank capacity. However, while the difference in peak flow retention efficiency followed the same trend, systems using short forecast lead-time could not deliver the same level of service compared to those using longer lead-time (Figure 2), even in unusually large systems (e.g. $15 \mathrm{~kL}$ ) (Figure 2). Such a finding highlights the importance of forecast information to the operation of RTC in mitigating flooding risks. Longer forecast period availability can be used to avoid the need for what would otherwise be larger storages to achieve the same level of flood mitigation performance. This can provide substantial benefits in highly dense urban environments, where flood protection is often prioritised (Nirupama \& Simonovic, 2006), but where space for flood storage may be limited. In addition, the smaller performance increase in large sized systems (Figure 2) also implies a diminishing-marginal-returns relationship with system capacity when using different forecast information and strategies to achieve optimal outcome across the multiple objectives. Considering the capital and space-take involved in building large storage, there is likely a benefit of using RTC to avoid requiring large storages, although large storages may still be required where overall water supply security is important. 


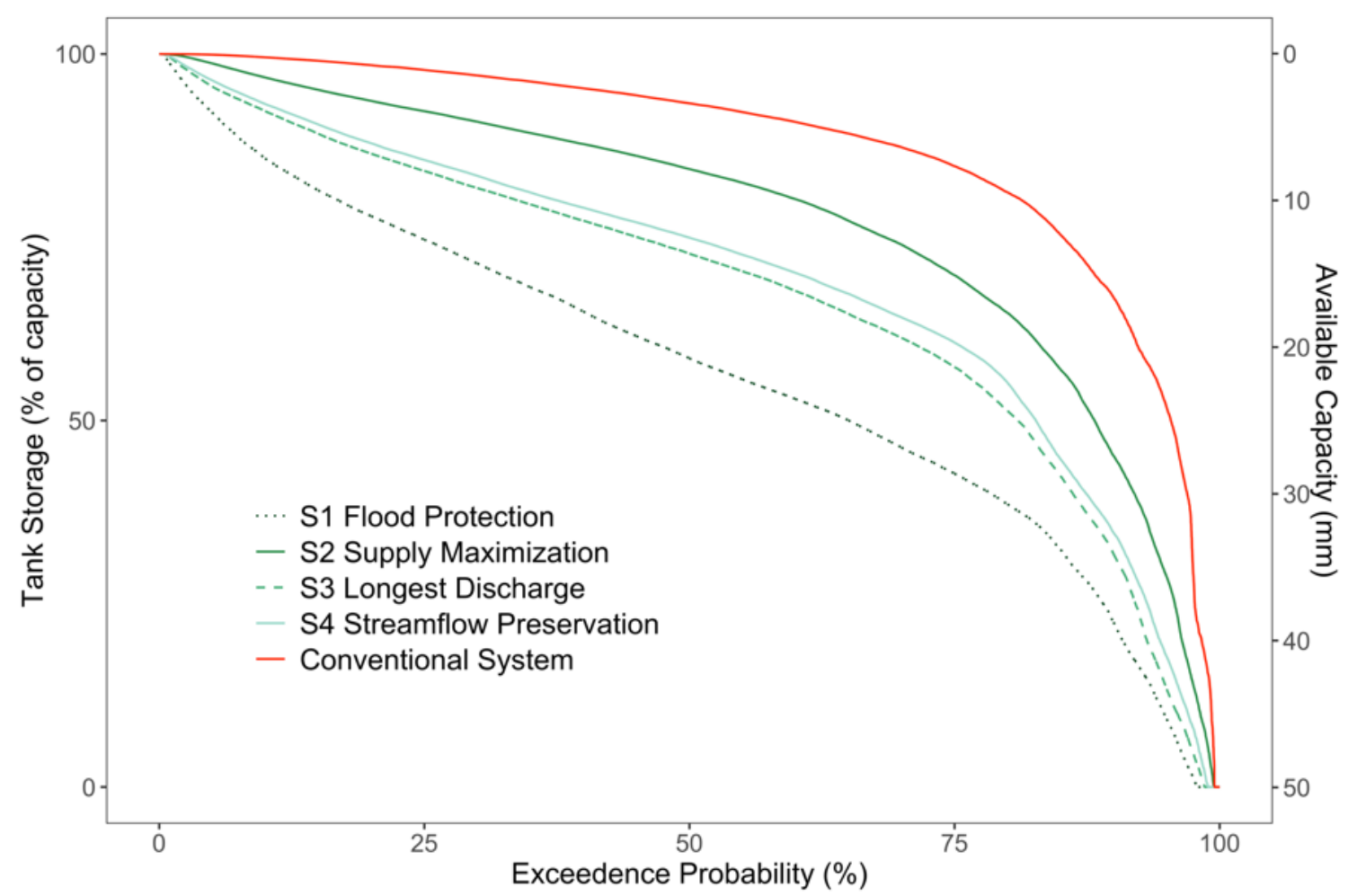

412

413

414

415

416

417

418

419

420

421

422

423

424

425

426

427

428

429

430

431

432

433

434

435

436

437

438

439

440

Figure 5. Tank storage duration curve of four RTC strategies compared with conventional systems. The available capacity (right $\mathrm{Y}$ axis expressed in mm of runoff from catchment) is the tank storage (kL) standardised linearly by roof size of $150 \mathrm{~m}^{2}$, expressed in $\mathrm{mm}$.

\subsection{The impact of outflow control}

Releasing the predicted overflow early over the forecast window can better reduce the flooding risks. Daily rainfall forecast generally does not provide the specific timing of the predicted storm events. This then makes the decision on the period of pre-storm release less certain, thus hindering the ability of RTC to create sufficient freeboard in time. Controlling the release early, such as occurs in S1 Flood Protection, can prepare empty space well before the actual storm events. But conversely, this leaves less water available for supply and baseflow release, albeit with benefits for retention performance of both the total runoff and flow peaks, which is vital for flood protection, especially in highly dense urban areas.

An RTC system without baseflow release is likely to achieve a similar level of flooding protection, through the pre-storm release. While increasing any type of consumption on tank water can help in making available headroom, thus enhancing the retention (flood mitigation) performance (DeBusk et al., 2013; Jones \& Hunt, 2010), RTC can overcome a lack of demand, ensuring releases of the right quantity and timing to reduce the likelihood of overflows. Both the design of baseflow and pre-storm release are based on this rationale - to proactively create additional headroom when water supply is insufficient to provide it. In the system without baseflow release, the volume, which would otherwise have gone to supporting downstream baseflow, will instead to be assigned to pre-storm release. Thus, any change (i.e. reduction or even elimination) of baseflow release would not significantly modify the modelling results observed in this study.

By definition, the period over which pre-storm releases occur will affect the proportion of time that the target baseflow is being achieved. Operation of the RTC in such a way to quickly release the pre-storm release (primarily to minimise flood risk) will have the impact of minimising time when above-baseflow flow rates are delivered. However, releasing flow early also increases the chance that there will be inadequate water available to 
meet the baseflow 'demand', meaning that the pre-storm release operation's effect on baseflow is a two-edged sword. Careful optimisation of these potentially conflicting objectives is necessary, to ensure that appropriate flow regimes and wetted habitats are available, particularly during dry periods (Leopold, 1968; Price, 2011).

However, reducing peak flow and maximising the period of base-flows may not necessarily achieve a full restoration of the flow regime. The ecological integrity of an aquatic ecosystem requires a flow regime as close as possible to its natural (pre-urbanisation) level (Poff et al., 1997). This includes, not only the magnitude and frequency of peak- and baseflow, but also the duration, timing and flashiness of flow events. Therefore, releasing the predicted overflow over a longer period at a lower rate, such as occurs in S3 Longest Discharge and S4 Streamflow Preservation (Figure 4), arguably better imitates the reference flow regime. Doing so also has the benefit of minimising the hydraulic disturbance and subsequent geomorphic degradation of the channels of receiving streams (Russell et al., 2020). In coupling with real-time flow monitoring (Kawanisi et al., 2018), RTC offers the potential to adapt the controlled release to real-time flow conditions, thus mimicking the natural streamflow, and delivering the flow regime determined appropriate for the ecological objectives of the receiving water.

A further consideration is the extent to which the pre-development or reference flow regime serves as a desirable ecological outcome. In this study, the reference stream showed significant periods of cease-to-flow conditions. In reality, many such natural streams will still experience flow during such periods, but it may be entirely hyporheic and not measured by standard flow gauges (Tonina, 2012). Regardless, there are broader ecological management questions about whether cease-to-flow conditions should be preserved (thus potentially contributing to regional biodiversity; (Poff et al., 2010)), or whether baseflow should be provided to increase local habitat and thus local biodiversity (Chiu et al., 2017). The RTC strategies we tested sought to maximise the period over which baseflow was sustained, but this could be easily adapted to mimic reference cease-to-flow conditions, if desired.

\subsection{Forecast Error}

The performance of RTC can be lost from forecast error. Precipitation forecast are subject to three types of error: localisation, timing and intensity of events (Habets et al., 2004). Location errors may lead to a prediction of rain that doesn't occur in reality (thus leading to unnecessary release and reduction in water supply reliability) or vice versa (leading to uncontrolled overflows). Timing errors for system using short lead-time forecast may result in the pre-storm release being too late to reduce overflow, but this will have much lower impact for long forecast lead-time strategies, such as S1 Flood Protection. More importantly, error in rainfall intensity is the main source of forecast uncertainty, especially on the daily time scale (Shahrban et al., 2016). Over-prediction causes unnecessary release leading detriment to reductions in yield. In contrast, underpredicting rainfall events, which is common in our simulation (see details of forecast error in the supporting information), can lead to the underestimation of pre-storm release volume, and so may reduce flood mitigation performance, especially in large events (e.g. 29th December 2016 event in Table 3). RTC using long-lead time forecast can potentially minimise the effect of such errors, given that the longer prediction window, as demonstrated above, allows RTC to prepare empty space for future events earlier (e.g. S1 Flood Protection). Future work could investigate the benefits and costs of RTC systems that use rainfall forecasts with lower probability (e.g. 10\% chance) to maximize the flood protection in large rainfall events. Another important future research 
area involves the exploration of how the RTC could adopt forecast with errors accounted for and thus minimize their impact on control outcomes.

It is of course likely that forecast accuracy will be improved in the future, thus informing a better control. Forecast accuracy can be improved by postprocessing the received Numeric Weather Prediction (NWP) (Shrestha et al., 2013), such as using Seasonality Coherent Calibration (Wang et al., 2019). Recent advances in downscaling NWP also offer RTC systems with finer spatial and temporal resolution 'nowcast' of upcoming storm events, such as Short Term Ensemble Prediction System (Bowler et al., 2006), which could better inform the pre-storm release in mitigating the flooding risks, especially in large events.

Our results showed that current forecast accuracy can affect the performance of RTC, but even so, the performance remains better than conventional systems. With growing advances in meteorology forecasting and better understanding on how to utilize the forecast information, the impact of forecast error on system performance could be minimized and even eliminated. Importantly, the impacts of forecast error on flood mitigation performance can be limited by use of long forecast lead-times, albeit with some cost in terms of water supply performance.

\subsection{Implementation}

Implementing RTC in rainwater harvesting systems is feasible. Such an application can be widely found in other urban water systems, such as water distribution networks (Leirens et al., 2010; Martínez et al., 2007) and combined sewers (Campisano et al., 2016; Mollerup et al., 2017). Current sensor technology enables the monitoring of present system states (e.g. pump flow, water level and valve status) and environmental condition (e.g. rainfall and streamflow) in real-time, which provides essential knowledge for RTC decision making (Schütze et al., 2004). Recent advances in low-cost sensors also provide an affordable and highly customized solution to tackle the technological and economical challenge during large scale implementation (Cherqui et al., 2019; Montserrat et al., 2013). The collected data and control decisions can be stored and transmitted through wireless communication and online platforms (Lefkowitz et al., 2016; Pellerin et al., 2016; Yang, 2006). Future broader adoption of RTC in stormwater management will, however, need to address the regulatory environment and governance. The operational jurisdiction and obscure ownership which characterise these systems, when applied at household scale, might slow down the development of the investment model for their ongoing effort for maintenance and deployment, which is likely to create inertia, impeding or delaying adoption (Brown \& Farrelly, 2009; Brown, 2005).

\subsection{Future Study}

Future research is required to investigate the spatio-temporal behaviour of networks of RTC-based systems. This includes the hydraulic modelling of the propagation released tank water through a catchment and its associated impact to the downstream receiving water. Algorithms, such as flood routing, could be incorporated to further understand the benefits of RTC on flood mitigation and flow regime restoration. More stochastic simulation of end-use behaviour is also essential to reveal the yield performance of RTC, and the human-behaviour and other factors that may affect it. Temporal variation in demand (e.g. short duration use) can impact the simulation of rainwater harvesting systems (Campisano \& Modica, 2016). However, in this study such variations are unlikely to modify the main conclusion, given the daily demand is small relative to the typical pre-storm release flows. Future consideration could also include various house configurations, such as different roof and tank sizes. All of 
these research questions will lead to a better overall understanding of the combined impacts of RTC systems.

Another very promising area of research is indeed the question of how multiple RTC systems can work collectively toward identified catchment-scale benefits. Application of RTC at different geographical locations could, for example, strategically adopt different release strategies to collectively meet the catchment-scale hydrological objective, both for the overall catchment and for various locations (sub-catchments) within the catchment. The investigation of such a distributed control strategy and assessment of its impact at catchment scales is a logical next step.

\section{Conclusion}

In this study, we aimed to design possible Real-Time Control (RTC) strategies to operate Rainwater Harvesting Systems and assess their effects using different forecast leadtimes. We modelled four strategies with different preferences in maximizing the benefits for water supply, flood protection or streamflow preservation. These strategies are based on different forecast lead-times (i.e. 1-day and 7-day rainfall forecasts) and are compared to a conventional system during a 5.5-year simulation period. We concluded that RTC systems yield comparatively less water supply yield than conventional systems only in small systems, but had much greater performance in reducing flood risks and restoring baseflow, for all test strategies. More importantly, using 7-day lead-time rainfall forecast, which offers longer prediction window, enhances the ability of RTC in mitigating flood risks, releasing water over a longer period and at a lower rate, thus delivering an outflow regime that is close to the reference streamflow. Such a finding indicates the promising potential of RTC to holistically restore natural flow regimes. This work provides valuable insights on both the advantages and trade-off of RTC applied to rainwater harvesting, and highlights the benefits and costs of using long lead-time forecast in control strategies. There are substantial opportunities for future adoption of RTC Rainwater Harvesting System in a range of contexts to achieve "smart" management of urban stormwater.

\section{Acknowledgments}

This research was made possible by the financial support from Melbourne Water, through the Melbourne Waterway Research-Practice Partnership (http://mwrpp.org) and from the European Union's Horizon 2020 research and innovation programme under Grant Agreement no. 786566 (https://mind4stormwater.org). Wei D. Xu received a Melbourne Research Scholarship provided by The University of Melbourne and South East Water Corporation. South East Water Corporation also provided operating expenses for this research. The support is gratefully acknowledged. The authors also thank South East Water Corporation (especially David Bergmann and Jeddah Breman) and Melbourne Water Corporation (especially Andrew Grant, Rhys Coleman and Sarah Watkins) for their intellectual input and guidance. We also would like to thank the three anonymous reviewers and the Associate Editor for their helpful suggestions and comments. The rainfall and streamflow data were sourced from Melbourne Water (https://www.melbournewater.com.au/water/rainfall-and-river-levels\#/) at Lysterfield station (228229B). The domestic water demand profile was adopted from Xu et al. (2018). The Rainfall forecast data were purchased from The Australian Digital Forecast Database, Australian Bureau of Meteorology (http://www.bom.gov.au/weatherservices/about/forecasts/australian-digital-forecast-database.shtml). 


\section{Reference}

Barron, O. V., Barr, A. D., \& Donn, M. J. (2013). Effect of urbanisation on the water balance of a catchment with shallow groundwater. Journal of Hydrology, 485(Supplement C), 162-176. doi:https://doi.org/10.1016/j.jhydrol.2012.04.027

Booth, Derek B., \& Jackson, C. Rhett. (1997). Urbanization of Aquatic Systems: Degradation Thresholds, Stormwater Detection, and the Limits of Mitigation. JAWRA Journal of the American Water Resources Association, 33(5), 1077-1090. doi:http://dx.doi.org/10.1111/j.1752-1688.1997.tb04126.x

Bowler, Neill E., Pierce, Clive E., \& Seed, Alan W. (2006). STEPS: A probabilistic precipitation forecasting scheme which merges an extrapolation nowcast with downscaled NWP. Quarterly Journal of the Royal Meteorological Society, 132(620), 2127-2155. doi:https://doi.org/10.1256/qj.04.100

Brown, R. R., \& Farrelly, M. A. (2009). Delivering sustainable urban water management: a review of the hurdles we face. Water Science \& Technology, 59(5), 839-846. doi:https://doi.org/10.2166/wst.2009.028

Brown, Rebekah R. (2005). Impediments to Integrated Urban Stormwater Management: The Need for Institutional Reform. Environmental Management, 36(3), 455-468. doi:https://doi.org/10.1007/s00267-004-0217-4

Bultot, F., Dupriez, G. L., \& Gellens, D. (1990). Simulation of land use changes and impacts on the water balance - A case study for Belgium. Journal of Hydrology, 114(3), 327348. doi:https://doi.org/10.1016/0022-1694(90)90064-5

Bunn, Stuart E., \& Arthington, Angela H. (2002). Basic Principles and Ecological Consequences of Altered Flow Regimes for Aquatic Biodiversity. Environmental Management, 30(4), 492-507. doi:https://doi.org/10.1007/s00267-002-2737-0

Bureau of Meteorology. (2010). Operational implementation of the ACCESS numerical weather prediction systems, NMOC, Operations Bulletin, No. 83. Retrieved from http://www.bom.gov.au/australia/charts/bulletins/apob83.pdf

Bureau of Meteorology. (2016). Design Rainfall Data System. Retrieved from http://www.bom.gov.au/water/designRainfalls/revised-ifd/

Bureau of Meteorology. (2020). The Australian Digital Forecast Database. Retrieved from http://www.bom.gov.au/weather-services/about/forecasts/australian-digital-forecastdatabase.shtml

Burns, Douglas, Vitvar, Tomas, McDonnell, Jeffrey, Hassett, James, Duncan, Jonathan, \& Kendall, Carol. (2005). Effects of suburban development on runoff generation in the Croton River basin, New York, USA. Journal of Hydrology, 311(1), 266-281. doi:https://doi.org/10.1016/j.jhydrol.2005.01.022

Burns, M. J., Fletcher, T. D., Duncan, H. P., Hatt, B. E., Ladson, A. R., \& Walsh, C. J. (2012a). The stormwater retention performance of rainwater tanks at the landparcel scale. Paper presented at the Proceedings of the 7th International Conference on Water Sensitive Urban Design, Melbourne, Australia.

Burns, Matthew J., Fletcher, Tim D., Walsh, Christopher J., Ladson, Anthony R., \& Hatt, Belinda E. (2012b). Hydrologic shortcomings of conventional urban stormwater management and opportunities for reform. Landscape and Urban Planning, 105(3), 230-240. doi:https://doi.org/10.1016/j.landurbplan.2011.12.012

Cai, Ximing, Hejazi, Mohamad I., \& Wang, Dingbao. (2011). Value of Probabilistic Weather Forecasts: Assessment by Real-Time Optimization of Irrigation Scheduling. Journal of Water Resources Planning and Management, 137(5), 391-403. doi:https://doi.org/10.1061/(ASCE)WR.1943-5452.0000126

Campisano, A., Creaco, E., \& Modica, C. (2016). Application of Real-Time Control Techniques to Reduce Water Volume Discharges from Quality-Oriented CSO 
Devices. Journal of Environmental Engineering, 142(1), 1-8. doi:https://doi.org/10.1061/(ASCE)EE.1943-7870.0001013

Campisano, Alberto, \& Modica, Carlo. (2016). Rainwater harvesting as source control option to reduce roof runoff peaks to downstream drainage systems. Journal of Hydroinformatics, 18(1), 23-32. doi:10.2166/hydro.2015.133

Cherqui, F. , Szota, C., James, R., Poelsma, P., Perigaud, T., Burns, M.J. , et al. (2019). Toward proactive management of stormwater control measures using low-cost technology. Paper presented at the 10th international conference NOVATECH, 1-5 July, Lyon, France.

Chiu, Ming-Chih, Leigh, Catherine, Mazor, Raphael, Cid, Núria, \& Resh, Vincent. (2017). Anthropogenic Threats to Intermittent Rivers and Ephemeral Streams. In T. Datry, N. Bonada, \& A. Boulton (Eds.), Intermittent Rivers and Ephemeral Streams (pp. 433454): Academic Press.

Clark, Martyn P., \& Hay, Lauren E. (2004). Use of Medium-Range Numerical Weather Prediction Model Output to Produce Forecasts of Streamflow. Journal of Hydrometeorology, 5(1), 15-32. doi:https://doi.org/10.1175/15257541(2004)005<0015:uomnwp>2.0.CO;2

Damrath, U., Doms, G., Frühwald, D., Heise, E., Richter, B., \& Steppeler, J. (2000). Operational quantitative precipitation forecasting at the German Weather Service. Journal of Hydrology, 239(1), 260-285. doi:https://doi.org/10.1016/S00221694(00)00353-X

Davies, T., Cullen, M. J. P., Malcolm, A. J., Mawson, M. H., Staniforth, A., White, A. A., et al. (2005). A new dynamical core for the Met Office's global and regional modelling of the atmosphere. Quarterly Journal of the Royal Meteorological Society, 131(608), 1759-1782. doi: https://doi.org/10.1256/qj.04.101

DeBusk, K.M., Hunt, W.F., \& Wright, J.D. (2013). Characterizing Rainwater Harvesting Performance and Demonstrating Stormwater Management Benefits in the Humid Southeast USA. Journal of the American Water Resources Association, 49(6), 13981411. doi:https://doi.org/10.1111/jawr.12096

DELWP. (2019). Schedule 2 to Clause 42.01 Environmental Significance Overlay - Little Stringybark Creek Catchment. Retrieved from http://planningschemes.delwp.vic.gov.au/schemes/yarraranges/ordinance/42_01s02_yran.pdf.

Di Matteo, M., Liang, R., Maier, H. R., Thyer, M. A., Simpson, A. R., Dandy, G. C., et al. (2019). Controlling rainwater storage as a system: An opportunity to reduce urban flood peaks for rare, long duration storms. Environmental Modelling \& Software, 111, 34-41. doi:https://doi.org/10.1016/j.envsoft.2018.09.020

Fewkes, A., \& Butler, D. (2000). Simulating the performance of rainwater collection and reuse systems using behavioural models. Building Services Engineering Research and Technology, 21(2), 99-106. doi:10.1177/014362440002100204

Fletcher, Tim D., Mitchell, Grace V., Deletic, Ana, Ladson, Tony R., \& Seven, Alain. (2007). Is stormwater harvesting beneficial to urban waterway environmental flows? Water Science and Technology, 55(4), 265-272. doi:https://doi.org/10.2166/wst.2007.117

Gardner, Ted, \& Vieritz, Alison. (2010). The role of rainwater tanks in Australia in the twenty first century. Architectural Science Review, 53(1), 107-125. doi:http://dx.doi.org/10.3763/asre.2009.0074

Gee, K. D., \& Hunt, W. F. (2016). Enhancing stormwater management benefits of rainwater harvesting via innovative technologies. Journal of Environmental Engineering, 142(8), 04016039. doi:https://doi.org/10.1061/(ASCE)EE.1943-7870.0001108

Georgakakos, Konstantine P., \& Hudlow, Michael D. (1984). Quantitative Precipitation Forecast Techniques for Use in Hydrologic Forecasting. Bulletin of the American 
Meteorological Society, 65(11), 1186-1200. doi:https://doi.org/10.1175/15200477(1984)065\%3C1186:Qpftfu\%3E2.0.Co;2

Haase, Dagmar. (2009). Effects of urbanisation on the water balance - A long-term trajectory. Environmental Impact Assessment Review, 29(4), 211-219. doi:https://doi.org/10.1016/j.eiar.2009.01.002

Habets, Florence, LeMoigne, Patrick, \& Noilhan, Joël. (2004). On the utility of operational precipitation forecasts to served as input for streamflow forecasting. Journal of Hydrology, 293(1), 270-288. doi:https://doi.org/10.1016/j.jhydrol.2004.02.004

Hamel, Perrine, Daly, Edoardo, \& Fletcher, Tim D. (2013). Source-control stormwater management for mitigating the impacts of urbanisation on baseflow: A review. Journal of Hydrology, 485, 201-211. doi:10.1016/j.jhydrol.2013.01.001

Hammer, Thomas R. (1972). Stream channel enlargement due to urbanization. Water Resources Research, 8(6), 1530-1540. doi:https://doi.org/10.1029/WR008i006p01530

Jenkins, D., Pearson, F., Moore, E., Sun, J. K., \& Valentine, R. (1978). Feasibility of rainwater collection systems in California. Contribution - California. University(No. 173).

Jones, Matthew P., \& Hunt, William F. (2010). Performance of rainwater harvesting systems in the southeastern United States. Resources, Conservation and Recycling, 54(10), 623-629. doi:https://doi.org/10.1016/j.resconrec.2009.11.002

Kawanisi, Kiyosi, Sawaf, Mohamad Basel Al, \& Danial, Mochammad Meddy. (2018). Automated Real-Time Streamflow Acquisition in a Mountainous River Using Acoustic Tomography. Journal of Hydrologic Engineering, 23(2), 04017059. doi:https://doi.org/10.1061/(ASCE)HE.1943-5584.0001604

Kerkez, Branko, Gruden, Cyndee, Lewis, Matthew, Montestruque, Luis, Quigley, Marcus, Wong, Brandon, et al. (2016). Smarter Stormwater Systems. Environmental Science \& Technology, 50(14), 7267-7273. doi:https://doi.org/10.1021/acs.est.5b05870

King, Ryan S., Baker, Matthew E., Whigham, Dennis F., Weller, Donald E., Jordan, Thomas E., Kazyak, Paul F., et al. (2005). Spatial Considerations for Linking Watershed Land Cover to Ecological Indicators in Streams. Ecological Applications, 15(1), 137-153. doi:https://doi.org/10.1890/04-0481

Laing, I.A.F., Denby, C.G., \& Prince, J.A. (1988). Design of roof runoff collection systems in Western Australia. Paper presented at the Hydrology and Water Resources Symposium 1988, ANU, Canberra.

Lefkowitz, Jamie R., Sarmanian, Alexa K., \& Quigley, Marcus. (2016). Continuous monitoring and adaptive control--the internet of things transforms stormwater management. Journal of New England Water Environment Association, 50(1), 44-51.

Leirens, S., Zamora, C., Negenborn, R. R., \& Schutter, B. De. (2010, 30 June-2 July 2010). Coordination in urban water supply networks using distributed model predictive control. Paper presented at the Proceedings of the 2010 American Control Conference.

Leopold, Luna B. (1968). Hydrology for Urban Land Planning - A Guidebook on the Hydrologic Effects of Urban Land Use (554). Retrieved from http://pubs.er.usgs.gov/publication/cir554

Liang, Ruijie, Matteo, Michael Di, Maier, Holger R., \& Thyer, Mark A. (2019). Real-Time, Smart Rainwater Storage Systems: Potential Solution to Mitigate Urban Flooding. Water, 11(12), 2428. doi:https://doi.org/10.3390/w11122428

Martínez, Fernando, Hernández, Vicente, Alonso, José Miguel, Rao, Zhengfu, \& Alvisi, Stefano. (2007). Optimizing the operation of the Valencia water-distribution network. Journal of Hydroinformatics, 9(1), 65-78. doi:https://doi.org/10.2166/hydro.2006.018 
Mikkelsen, P., Adeler, O., Albrechtsen, H., \& Henze, M. (1999). Collected rainfall as a water source in danish households - what is the potential and what are the costs? Water Science and Technology, 39(5), 49-56. doi:10.1016/s0273-1223(99)00086-4

Mitchell, V. G., Siriwardene, N., Duncan, H., \& Rahilly, M. (2008). Investigating the Impact of Temporal and Spatial Lumping on Rainwater Tank System Modelling. Paper presented at the Proceedings of Water Down Under 2008.

Mollerup, A. L., Mikkelsen, P. S., Thornberg, D., \& Sin, G. (2017). Controlling sewer systems - a critical review based on systems in three EU cities. Urban Water Journal, 14(4), 435-442. doi:https://doi.org/10.1080/1573062X.2016.1148183

Montserrat, A., Gutierrez, O., Poch, M., \& Corominas, Ll. (2013). Field validation of a new low-cost method for determining occurrence and duration of combined sewer overflows. Science of The Total Environment, 463-464, 904-912. doi:https://doi.org/10.1016/j.scitotenv.2013.06.010

Nirupama, N., \& Simonovic, Slobodan P. (2006). Increase of Flood Risk due to Urbanisation: A Canadian Example. Natural Hazards, 40(1), 25. doi:https://doi.org/10.1007/s11069006-0003-0

Pellerin, Brian A., Stauffer, Beth A., Young, Dwane A., Sullivan, Daniel J., Bricker, Suzanne B., Walbridge, Mark R., et al. (2016). Emerging Tools for Continuous Nutrient Monitoring Networks: Sensors Advancing Science and Water Resources Protection. Journal of the American Water Resources Association, 52(4), 993-1008. doi:https://doi.org/10.1111/1752-1688.12386

Poff, N. LeRoy, Allan, J. David, Bain, Mark B., Karr, James R., Prestegaard, Karen L., Richter, Brian D., et al. (1997). The Natural Flow Regime. BioScience, 47(11), 769784. doi:https://doi.org/10.2307/1313099

Poff, N. Leroy, Richter, Brian D., Arthington, Angela H., Bunn, Stuart E., Naiman, Robert J., Kendy, Eloise, et al. (2010). The ecological limits of hydrologic alteration (ELOHA): a new framework for developing regional environmental flow standards. Freshwater Biology, 55(1), 147-170. doi:https://doi.org/10.1111/j.1365-2427.2009.02204.x

Price, Katie. (2011). Effects of watershed topography, soils, land use, and climate on baseflow hydrology in humid regions: A review. Progress in Physical Geography: Earth and Environment, 35(4), 465-492. doi:https://doi.org/10.1177/0309133311402714

Roman, David, Braga, Andrea, Shetty, Nandan, \& Culligan, Patricia. (2017). Design and Modeling of an Adaptively Controlled Rainwater Harvesting System. Water, 9(12), 974. doi:https://doi.org/10.3390/w9120974

Rossa, Andrea, Liechti, Katharina, Zappa, Massimiliano, Bruen, Michael, Germann, Urs, Haase, Günther, et al. (2011). The COST 731 Action: A review on uncertainty propagation in advanced hydro-meteorological forecast systems. Atmospheric Research, 100(2), 150-167. doi:https://doi.org/10.1016/j.atmosres.2010.11.016

Russell, Kathryn L, Vietz, Geoff J, \& Fletcher, Tim D. (2020). How urban stormwater regimes drive geomorphic degradation of receiving streams. Progress in Physical Geography: Earth and Environment, 1-33. doi:https://doi.org/10.1177/0309133319893927

Schubert, Jochen E., Burns, Matthew J., Fletcher, Tim D., \& Sanders, Brett F. (2017). A framework for the case-specific assessment of Green Infrastructure in mitigating urban flood hazards. Advances in Water Resources, 108, 55-68. doi:https://doi.org/10.1016/j.advwatres.2017.07.009

Schütze, Manfred, Campisano, Alberto, Colas, Hubert, Schilling, Wolfgang, \& Vanrolleghem, Peter A. (2004). Real time control of urban wastewater systems - where do we stand 
today? Journal of Hydrology, 299(3-4), 335-348. doi:http://dx.doi.org/10.1016/j.jhydrol.2004.08.010

Shahrban, Mahshid, Walker, Jeffrey P., Wang, Q. J., Seed, Alan, \& Steinle, Peter. (2016). An evaluation of numerical weather prediction based rainfall forecasts. Hydrological Sciences Journal, 61(15), 2704-2717. doi:https://doi.org/10.1080/02626667.2016.1170131

Shrestha, D. L., Robertson, D. E., Wang, Q. J., Pagano, T. C., \& Hapuarachchi, H. A. P. (2013). Evaluation of numerical weather prediction model precipitation forecasts for short-term streamflow forecasting purpose. Hydrol. Earth Syst. Sci., 17(5), 1913-1931. doi:https://doi.org/10.5194/hess-17-1913-2013

Smakhtin, V U. (2001). Low flow hydrology: a review. Journal of Hydrology, 240(3-4), 147186. doi:http://doi.org/10.1016/S0022-1694(00)00340-1

Smakhtin, V. Y., Hughes, D. A., \& Creuse-Naudin, E. (1997). Regionalization of daily flow characteristics in part of the Eastern Cape, South Africa. Hydrological Sciences Journal, 42(6), 919-936. doi:https://doi.org/10.1080/02626669709492088

Tonina, Daniele. (2012). Surface water and streambed sediment interaction: The hyporheic exchange. In C. Gualtieri \& D. T. Mihailović (Eds.), Fluid Mechanics of Environmental Interfaces (pp. 255-294). CRC Press: Taylor \& Francis Group.

Tsai, Frank T. C., Katiyar, Vineet, Toy, Doug, \& Goff, Robert A. (2008). Conjunctive Management of Large-Scale Pressurized Water Distribution and Groundwater Systems in Semi-Arid Area with Parallel Genetic Algorithm. Water Resources Management, 23(8), 1497. doi:https://doi.org/10.1007/s11269-008-9338-5

Vörösmarty, C. J., McIntyre, P. B., Gessner, M. O., Dudgeon, D., Prusevich, A., Green, P., et al. (2010). Global threats to human water security and river biodiversity. Nature, 467(7315), 555-561. doi:https://doi.org/10.1038/nature09440

Walsh, C. J., Fletcher, Tim D., \& Burns, Matthew J. (2012). Urban Stormwater Runoff: A New Class of Environmental Flow Problem. PLoS ONE, 7(9), 1-10. doi:https://doi.org/10.1371/journal.pone.0045814

Walsh, Christopher J., Booth, Derek B., Burns, Matthew J., Fletcher, Tim D., Hale, Rebecca L., Hoang, Lan N., et al. (2016). Principles for urban stormwater management to protect stream ecosystems. Freshwater Science, 35(1), 398-411. doi:10.1086/685284

Wang, Dingbao, \& Cai, Ximing. (2009). Irrigation Scheduling - Role of Weather Forecasting and Farmers' Behavior. Journal of Water Resources Planning and Management, 135(5), 364-372. doi:https://doi.org/10.1061/(ASCE)0733-9496(2009)135:5(364)

Wang, Q. J., Zhao, Tony, Yang, Qichun, \& Robertson, David. (2019). A Seasonally Coherent Calibration (SCC) Model for Postprocessing Numerical Weather Predictions. Monthly Weather Review, 147(10), 3633-3647. doi:https://doi.org/10.1175/mwr-d19-0108.1

Westphal, Kirk S., Vogel, Richard M., Kirshen, Paul, \& Chapra, Steven C. (2003). Decision Support System for Adaptive Water Supply Management. Journal of Water Resources Planning and Management, 129(3), 165-177. doi:https://doi.org/10.1061/(ASCE)0733-9496(2003)129:3(165)

$\mathrm{Xu}$, Wei, Fletcher, Tim, Duncan, Hugh, Bergmann, David, Breman, Jeddah, \& Burns, Matthew. (2018). Improving the Multi-Objective Performance of Rainwater Harvesting Systems Using Real-Time Control Technology. Water, 10(2), 147. doi:https://doi.org/10.3390/w10020147

Yang, T.C. (2006). Networked control system: a brief survey. IEE Proceedings - Control Theory and Applications, 153(4), 403-412. doi:http://dx.doi.org/10.1049/ipcta:20050178 
Input Data

Rainfall Forecast
Tank Capacity
Roof Area
End-use Demand
(Daily)
Baseflow Target
(Daily)
Initial Leve1
Rolling Horizon
(15:00 pm daily)

Rainfall (6-min)

Tank Capacity

Roof Area

End-use Demand (6min)

Baseflow Target (6min)

Initial Level
Simulation Module

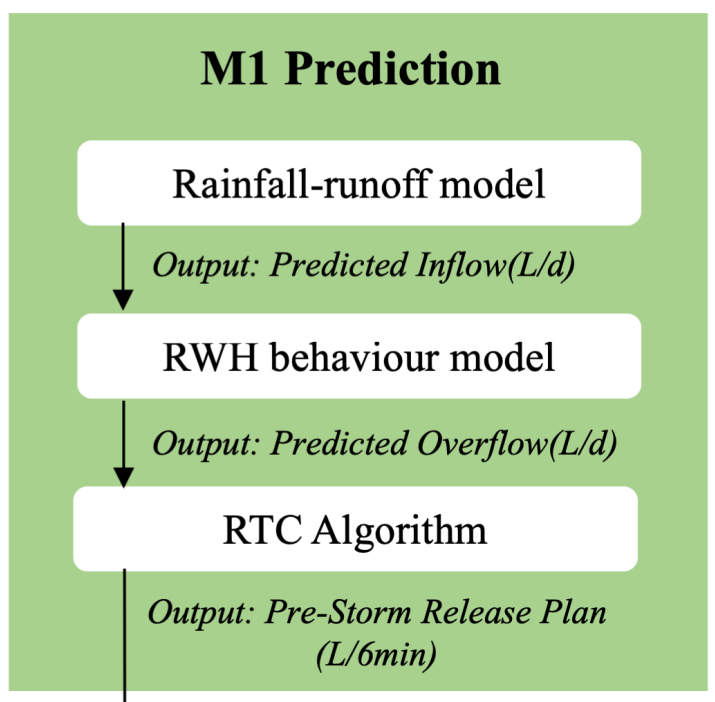

RTC Algorithm (L/6min)

\section{M2 Simulation}

Rainfall-runoff model

Output: Inflow(L/d)

RWH behaviour model

Output:

(1) Release (L/6min, including baseflow and pre-storm release)

(2) Tank Level (L)

(3) Overflow (L/6min)

(4) Water Supply (L/6min)

\section{M3 Evaluation}

\section{Assessment Metrics}

Baseflow Target (6min)

End-use Demand (6min)
Overflow Prediction

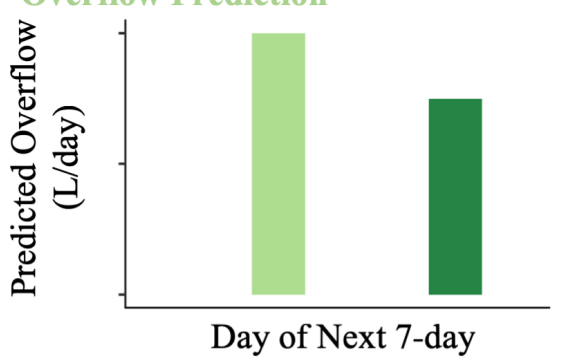

Controlled Release Under Four Strategies

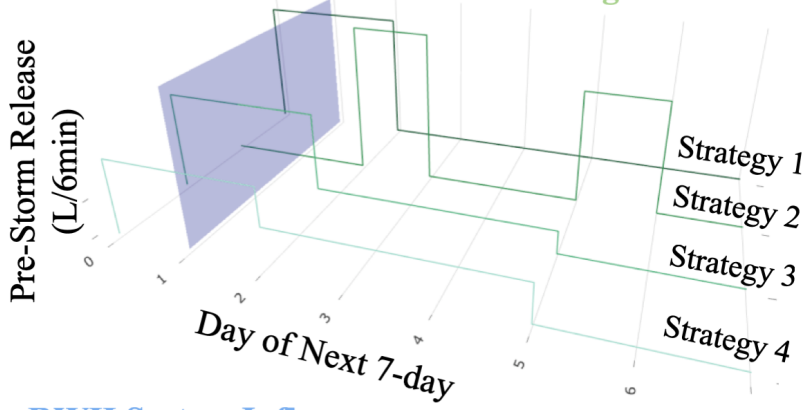

RWH System Inflow 突 哭

RWH System Behaviour
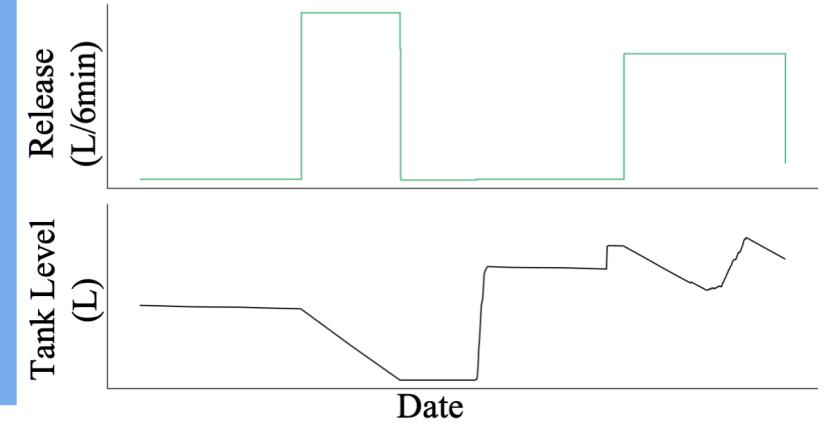

Assessment Metrics

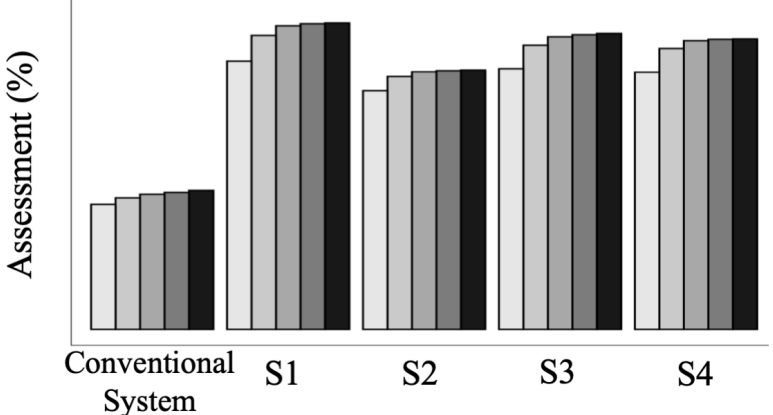


Figure 2.
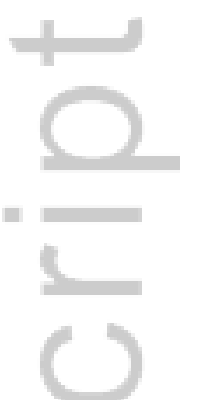

$\infty$
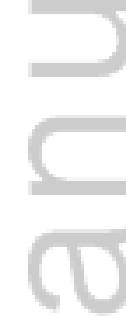

This article is protected by copyright. All rights reserved. 


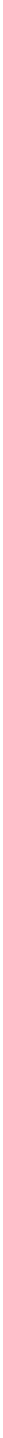


Figure 5.
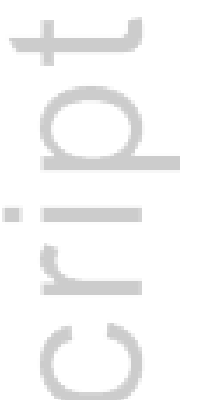

$\infty$
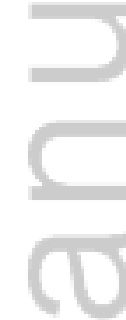

This article is protected by copyright. All rights reserved. 


\section{University Library}

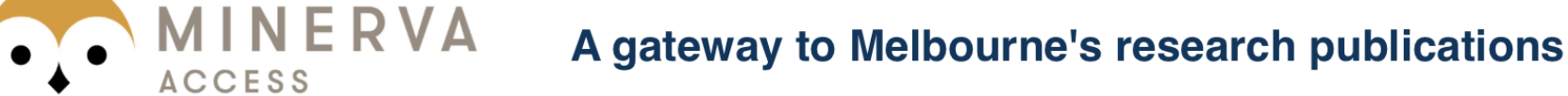

Minerva Access is the Institutional Repository of The University of Melbourne

Author/s:

Xu, WD;Fletcher, TD;Burns, MJ;Cherqui, F

Title:

Real Time Control of Rainwater Harvesting Systems: The Benefits of Increasing Rainfall Forecast Window

Date:

2020-09

Citation:

Xu, W. D., Fletcher, T. D., Burns, M. J. \& Cherqui, F. (2020). Real Time Control of Rainwater Harvesting Systems: The Benefits of Increasing Rainfall Forecast Window. Water Resources Research, 56 (9), https://doi.org/10.1029/2020wr027856.

Persistent Link:

http://hdl.handle.net/11343/242412 